\title{
ENCUENTRO NICARAGUA 1979-2019: DE LA REVOLUCIÓN A LA INSURRECCIÓN
}

\author{
Sergio Villena Fiengo \\ Instituto de Investigaciones Sociales, \\ Universidad de Costa Rica, Costa Rica
}

Recibido: 18-02-2020 / Aceptado: 01-03-2020

\begin{abstract}
Resumen
El Encuentro Nicaragua 1979-2019: De la Revolución a la insurrección se realizó entre el 26 y el 30 de agosto del 2019, en la Universidad de Costa Rica, con la coordinación general del Instituto de Investigaciones Sociales y con el apoyo de la Vicerrectoría de Acción Social. El objetivo general del Encuentro fue reunir una pluralidad de actores y analistas que, haciendo énfasis en las voces silenciadas y en las zonas grises de la historia oficial, realizaran un balance de lo ocurrido en Nicaragua en esas cuatro décadas, enmarcadas por dos momentos clave de la historia, el triunfo de la Revolución en 1979 y la insurrección cívica de 2018. Con una excepción, todas las actividades fueron presenciales, en el Instituto de Investigaciones Sociales, la Sede del Pacífico y la Sede de Occidente, y se transmitieron en tiempo real por Facebook Live. Las grabaciones se encuentran a disposición del público en el sitio web del IIS, mediante el siguiente enlace: https://iis.ucr.ac.cr/index.php/recursos/encuentro. Este texto presenta una relatoría general y comprensiva del Encuentro y sus actividades preparatorias.
\end{abstract}




\section{Antecedentes}

En mayo llegan las primeras lluvias.

La hierba tierna renace de las cenizas.

Los lodosos tractores roturan la tierra.

Los caminos se llenan de mariposas y de charcos, y las noches son frescas, y cargadas de insectos,

y llueve toda la noche. En mayo florecen los malinches en las calles de Managua. Pero abril en Nicaragua es el mes de la muerte.

En abril los mataron.

Ernesto Cardenal

El 19 de julio de 1979, la historia experimentó un hecho inédito en Centroamérica: el triunfo de un movimiento revolucionario en Nicaragua. Ese acontecimiento marcó intensamente la vida del Istmo durante la siguiente década; por un lado, parecía el comienzo de una profunda transformación en beneficio de las grandes mayorías; por otro, Centroamérica devenía en -unos años más tarde sabríamos que el último-escenario de la Guerra Fría, estallando una "guerra subsidiaria" que involucraría, de una u otra forma, a todos los países del área en el conflicto y en la búsqueda de su solución.

Cuarenta años han pasado desde el triunfo de la Revolución sandinista y poco menos de treinta desde que el gobierno surgido de ese acontecimiento llegara a su fin. El conflicto armado frente a la Contra, respaldada por el gobierno de Reagan, forzó en 1990 al gobierno sandinista a convocar a elecciones adelantadas, en las cuales salió derrotado frente a la oposición aglutinada tras la UNO y la candidatura de Violeta Barrios de Chamorro. El FSLN entregó pacíficamente el gobierno a la presidenta electa, no sin antes realizar un cuestionado proceso de apropiación partidista y personal -denominado popularmente "la piñata sandinista" - de bienes expropiados a somocistas y otros sectores señalados como contrarrevolucionarios por el gobierno sandinista.

A partir de ese momento, Nicaragua entró en un ciclo de gobiernos democráticos de "baja intensidad", crecientemente orientados hacia las políticas neoliberales. El sandinismo, por su parte, pasaba por un proceso de fragmentación, surgiendo un ala disidente, el Movimiento Sandinista de Renovación (MSR). El FSLN, controlado por Daniel Ortega, pasó a convertirse en el principal partido de oposición durante los gobiernos de Violeta Barrios, Arnoldo Alemán y Enrique Bolaños. Luego de varios intentos fallidos, en el año 2006, Daniel Ortega y el FSLN resultaron vencedores en las elecciones nacionales, volviendo a controlar el ejecutivo, el cual mantienen hasta el presente, gracias a dos cuestionados procesos reeleccionarios de por medio. 
El retorno de Ortega y el Frente al gobierno se dio en un contexto latinoamericano relativamente favorable, en el que emergía un conjunto de gobiernos enmarcados en el denominado "socialismo del siglo XXI". Pero el sandinismo en el poder, pese a que a nivel internacional se afiliaba al "progresismo pos-neoliberal" y se beneficiaba de la ayuda venezolana, no era el mismo que había gobernado el país en la década de los ochenta. El "nuevo sandinismo" arribaba por la vía democrática, algo sin duda positivo, pero lo hacía estableciendo una serie de acuerdos poco progresistas con sectores con los cuales se había enfrentado de manera frontal en las décadas pasadas. Pactaba con los liberales y su líder, el expresidente Arnoldo Alemán; pactaba con el gran capital, agrupado en el COSEP; pactaba con los sectores más conservadores de la Iglesia católica, en especial con el cardenal Obando y Bravo.

Así, Daniel Ortega y su esposa Rosario Murillo, que devendría vicepresidenta, buscaban asegurarse el poder implementando una agenda que favorecía a políticos cuestionados, empresarios depredadores y religiosos ultraconservadores. Asimismo, realizaba una serie de movidas que procuraban una creciente patrimonialización del Estado por la familia gobernante y sus allegados, estableciendo también una política clientelar con los sectores populares afines. Con todo ello, el sandinismo, pese a declararse histriónicamente "socialista, cristiano y solidario", se alejaba cada vez más del legado de Sandino, de su pasado socialista y de la Teología de la liberación. De esa forma, erosionaba su imagen revolucionaria y echaba por la borda los avances sociales obtenidos durante el primer gobierno sandinista y apenas conservados durante los gobiernos posteriores, así como ponía fin a los incipientes logros democráticos a duras penas establecidos a partir de 1990.

Como consecuencia, se fueron acumulando una serie de agravios perpetrados por el gobierno y sus adherentes hacia el resto de la sociedad nicaragüense, la cual, si bien se beneficiaba de algunos logros en términos de crecimiento económico y de seguridad ciudadana, al mismo tiempo constataba que sus derechos ciudadanos y la institucionalidad democrática se iban desgastando, situación que resentía especialmente la clase media emergente. Pero también se deterioraban las condiciones materiales de amplios sectores populares, ya que la expansión del gran capital -incluida la inversión extranjera- y la política clientelista hacia los sectores populares afines al FSLN, conducían a generar crispación, sobre todo entre los sectores campesinos e indígenas, que veían amenazados sus territorios y recursos por una política extractivista que favorecía a sectores mineros, turísticos y de infraestructura. En los años recientes, esas tendencias se exacerbaron con el proyecto de construcción del canal interoceánico y con la expansión de la frontera agrícola mediante la ocupación de áreas protegidas.

A esos malestare se sumaron los relacionados con la disciplicente respuesta gubernamental a los incendios en la reserva Indio Maíz, así como los provocados por las reformas al régimen de pensiones. El resultado de esa acumulación de agravios y tensiones fue el estallido espontáneo de una insurrección cívica en abril de 2018, la cual 
fue respondida por el gobierno con una feroz represión que dejó al menos 300 muertos, así como cientos de heridos, detenidos y refugiados. La implantación del terror estatal y paramilitar, combinado con las dificultades que ha mostrado la oposición para armar una coalición unitaria y una propuesta bien articulada para una eventual "transición", hace pensar que de ocurrir esta, no será mediante una negociación o pacto ("transición pactada"), sino por el colapso del régimen, que si bien parece haber sofocado la rebelión, permanece entrampado en sus propias contradicciones. ${ }^{1}$

El Encuentro Nicaragua 1979-2019: De la revolución a la insurrección pretende ser un espacio de reflexión sobre el periodo histórico esbozado en los párrafos precedentes. Su objetivo fue reunir una pluralidad de actores y analistas que, haciendo énfasis en las voces silenciadas y en las zonas grises de la historia oficial, realizaran un balance de lo ocurrido en Nicaragua en esas cuatro décadas. Mediante ese ejercicio, se buscaba revisitar las interrogantes que permanecen abiertas en relación con la Revolución sandinista, a la luz de la coyuntura que estalla con la insurrección cívica de abril de 2018. La premisa de partida es que el momento actual plantea una serie de interrogantes, que ganan relevancia no solo en relación con la crisis reciente, sino en términos del vínculo entre el presente insurrecto y el pasado revolucionario.

Así, el Encuentro exploró nuevas respuestas a "viejas" interrogantes: ¿Cuáles fueron las causas de la revolución sandinista? ¿Cómo fue posible el triunfo revolucionario? ¿Cuáles fueron las características del gobierno revolucionario? ¿Cómo se explica su caída? ¿Cuál es su legado? Pero también propone interrogantes sobre la coyuntura actual y su relación con el pasado periodo revolucionario: ¿Cuál es la actualidad de la revolución sandinista en la región? ¿Cuál fue el papel del sandinismo durante el periodo democrático inaugurado en 1990? ¿Cuál es la relación entre el segundo gobierno sandinista que inicia en el año 2006 y se mantiene hasta la actualidad, con el sandinismo histórico del periodo revolucionario? ¿Cómo se explica el estallido insurrecciónal actual en Nicaragua? ¿Cuáles son las similitudes y diferencias de esta movilización masiva con la ocurrida cuarenta años atrás? ¿Cuáles son los escenarios que el estallido de 2018 abre para la sociedad nicaraguënse?

\section{El Encuentro}

El programa del Encuentro incluyó un total de quince actividades, como presentaciones de libros, foros, conferencias, exposiciones de resultados de talleres y presentaciones musicales. Para este evento se contó con la participación de un amplio número de ponentes y conferencistas, entre quienes destacan tres prestigiosas académicas internacionales invitadas: la Dra. Ileana Rodríguez (Universidad de Ohio y CALAS), la Dra. Verónica Rueda (Universidad de Quintana Roo) y la Dra. Dolores Figueroa (CIESAS, Ciudad de México). Asimismo, participó el Dr. Aleksander Aguilar 
(Universidad de Pelotas, Brasil), auspiciado por CLACSO, así como los artistas nicaragüenses Mario Rocha y Chelo B, este último financiado parcialmente por la Iniciativa Universitaria por Nicaragua.

La actividad involucró, además de las ya mencionadas, a personas académicas expertas en la historia y el presente de Nicaragua, provenientes de ese país (varios refugiados que huyeron de la represión gubernamental reciente, pero también otros residentes en Costa Rica), de Costa Rica y de otras latitudes, quienes participaron como conferencistas, panelistas, ponentes, comentaristas y moderadores. Se privilegiaron las voces silenciadas de la historia y aquello que la Dra. Rodríguez denomina "la prosa de la contrainsurgencia"; se promovió en todo momento un enfoque dialógico, crítico, transversal, interdisciplinario, intergeneracional, inter y transgenérico, étnicamente diverso, transfronterizo y socialmente plural.

El Encuentro fue organizado por el Instituto de Investigaciones Sociales (IIS) de la Universidad de Costa Rica (UCR), con el apoyo de diversas instancias institucionales. En la UCR, la Vicerrectoría de Acción Social (VAS) aportó buena parte de los recursos económicos para la actividad, la Oficina de Asuntos Internacionales y Cooperación Externa (OAICE) financió a dos invitadas internacionales, la Sede Regional del Pacífico (SRP) gestionó el arribo de una invitada y organizó las actividades en Puntarenas, el Centro de Investigaciones sobre Diversidad Cultural y Estudios Regionales de la Sede de Occidente (CIDICER/SO) organizó las actividades en San Ramón, la Oficina de Divulgación e Información (ODI) colaboró con la difusión y cobertura, la cual fue apoyada también por Radio Universidad. Externamente, se contó con el apoyo de la Iniciativa Universitaria por Nicaragua, de la FLACSO Sede Costa Rica, así como del CLACSO y la red O Istmo (Figura 1 y Figura 2). 
Figura 1

AFICHE DE LA CONVOCATORIA REALIZADA POR EL IIS



Figura 2

AFICHE DE LA CONVOCATORIA REALIZADA POR EL IIS

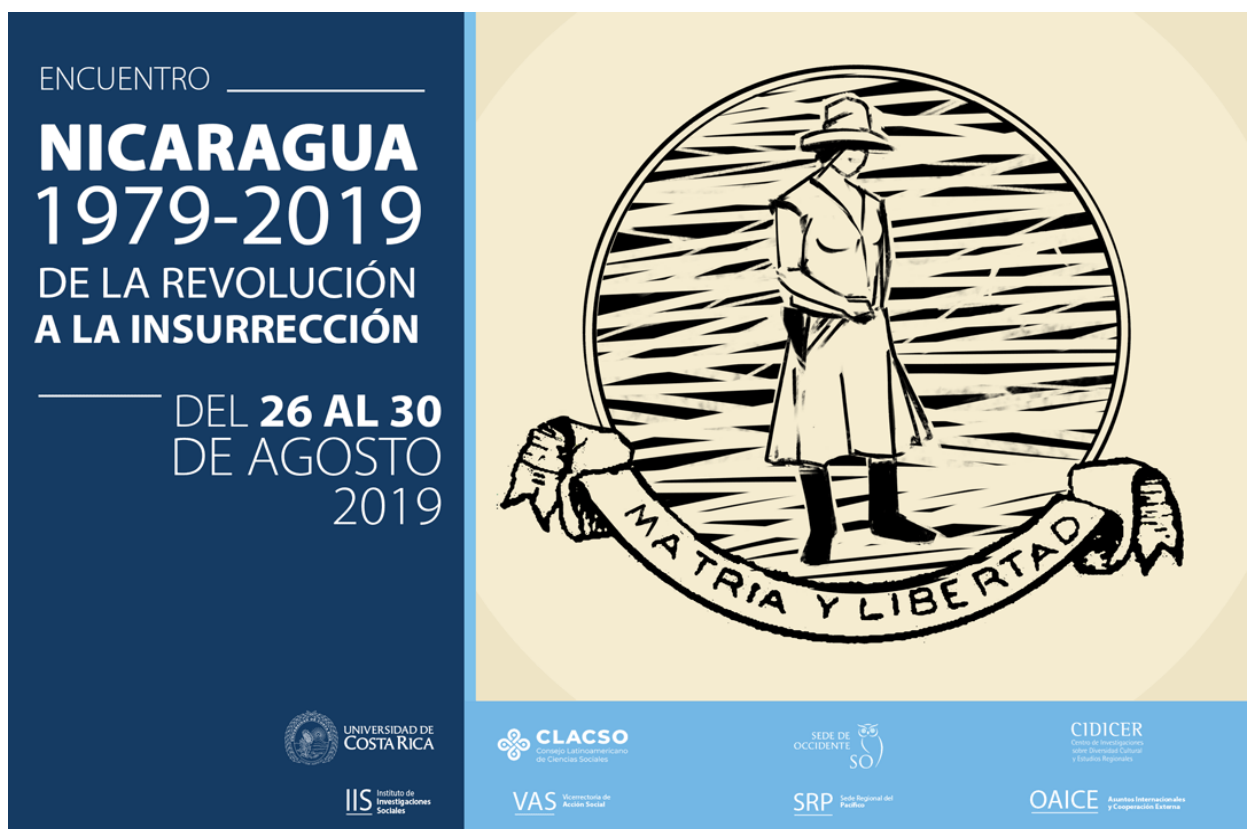




\section{Programa efectivo}

\section{Lunes 26 de agosto del 2019, Auditorio IIS}

1) Presentación del libro Nicaragua en Crisis: Entre la revolución y la rebelión, compilado por Aleksander Aguilar, Esteban de Gori y Carmen Elena Villacorta, publicado en su segunda edición por CLACSO, 2019.

Panelistas: Aleksander Aguilar (coeditor), Verónica Rueda (autora), Darvin Sánchez (autor), Dolores Figueroa (comentarista) y Sergio Villena (moderador).

Luego de unas palabras de bienvenida y apertura del Encuentro, a cargo de Sergio Villena, Aguilar relató la historia sobre cómo surgió el libro, la manera en la cual se contactó a las personas autoras y cómo se estructuró el texto. Por su parte, Rueda presentó su contribución "'Que se rinda tu madre'. Los nuevos/viejos símbolos y tácticas de la movilización social en Nicaragua", en tanto que Sánchez expuso el capítulo "Protesta social en Nicaragua: ¿derecho o delito?". La presentación de libro funcionó como actividad de apertura del Encuentro; se plantearon diversas aristas sobre la crisis que enfrenta Nicaragua desde abril del 2018 y se invitó a revisitar el pasado -particularmente los 40 años transcurridos desde el triunfo de la Revolución sandinista-, para entender mejor la coyuntura actual e imaginar un futuro más promisorio para Nicaragua.

2) Mesa Memoria e Historia. El rol del Movimiento Estudiantil desde la Revolución Sandinista, organizada por la Iniciativa Universitaria por Nicaragua.

Participaron tres estudiantes nicaragüenses refugiados en Costa Rica, con la moderación de Diana Campos, de la Iniciativa Universitaria por Nicaragua. Se plantearon principalmente asuntos relativos a la participación de las personas jóvenes universitarias en la insurrección cívica del 2018, así como la situación crítica por la que atraviesan las universidades -en cuanto a la autonomía universitaria y la calidad de la enseñanzaen el contexto de la crisis actual.

3) Conferencia Recompas, recontras, revueltos y rearmados. Posguerra y conflictos por la tierra en Nicaragua 1990-2008.

Conferencista: Verónica Rueda. Comentarista: Irene Agudelo (UCA Nicaragua). Moderador: Sergio Villena.

La conferencista expuso a partir de su libro homónimo, el cual se centra en la posguerra y la problemática de los desmovilizados en la década de los 1990; Rueda destacó la conformación diversa de la contra y el incumplimiento de los ofrecimientos realizados a los desmovilizados por el gobierno de Violeta Barrios. Además, expuso las características de la nueva movilización y el retorno a las armas por diversos actores: 
recompas, recontras, rearmados y revueltos (y remujeres). En su comentario, Agudelo destacó los aportes de Rueda a la historiografía de la contra y de la posguerra, enfatizando también en las particularidades metodológicas de la historia oral. Adicionalmente, la comentarista aportó -con base en su libro Contramemorias- algunos elementos sobre la construcción -desde el sandinismo- del contra como enemigo y sobre algunas particularidades del tema de género en la contra.

\section{Martes 27 de agosto del 2019, Sede del Pacífico (Puntarenas)}

4) Mesa redonda Nicaragua a 40 años de la Revolución Sandinista.

Participantes: Ileana Rodríguez, Verónica Rueda Estrada, Dolores Figueroa Romero Moderadora: María Barboza Gutiérrez (Sede del Pacífico).

De acuerdo con el guion predefinido y ante un público formado principalmente por profesores y estudiantes de la Sede, se recorrieron las distintas etapas transcurridas entre el triunfo de la revolución y el momento actual, desde distintos puntos de vista y enfatizando la problemática de género, la cuestión agraria y la situación de las poblaciones de la costa.

5) Conferencia El movimiento de los contras en Nicaragua

Conferencista: Verónica Rueda. Moderador: David Chavarría Camacho (Sede del Pacífico).

La conferencista profundizó en la problemática de la contra y su relación con la cuestión agraria, especialmente de las particularidades, limitaciones y resistencias que generó la reforma agraria sandinista, así como de la manera que esa compleja problemática fue tratada por el gobierno y otros sectores durante el periodo de posguerra.

\section{Miércoles 28 de agosto del 2019 Sede de Occidente (San Ramón)}

6) Mesa redonda Nicaragua a 40 años de la Revolución Sandinista.

Panelistas: Ileana Rodríguez, Verónica Rueda, Dolores Figueroa. Moderador: Miguel Ángel Herrera Cuarezma (Sede de Occidente).

Luego de unas palabras de bienvenida de la Dra. Luz Marina Vázquez, directora del CIDICER, inició la mesa redonda. Siguiendo las mismas pautas de la actividad realizada el día anterior en Puntarenas y ante un público conformado principalmente por estudiantes y profesores de la Sede, las panelistas hicieron un recuento crítico de los problemas sociales por los que atravesó la sociedad nicaragüense en los distintos momentos que siguieron al triunfo revolucionario de 1979. 
7) Conferencia La región Atlántica en la revolución y después, por Dolores Figueroa Romero. Comentarista: Denia Román Solano (Escuela de Antropología, CLACSO y red O Istmo).

La conferencista hizo un recuento detallado de la problemática de la costa atlántica nicaragüense, antes, durante y después de la revolución. Comenzó en el periodo somocista, continuó con lo acontecido durante el gobierno del FSLN y luego habló sobre la transición hacia la democracia. Por su parte, la comentarista puntualizó lo señalado por Dolores Figueroa e introdujo algunos elementos comparativos con otros procesos autonómicos, en particular con el que se está llevando a cabo en el sur de México, que propuso como un modelo para fortalecer "desde abajo" el proceso autonómico nicaragüense.

En esta actividad se amplió el programa para dar la oportunidad a la líder Susan Marley Cunningham, Tata Mama miskita, para referirse a la situación de las comunidades étnicas que pueblan la costa Caribe de Nicaragua. Ella hizo un recuento de los sucesivos incumplimientos de los acuerdos tomados por distintos gobiernos con estas poblaciones, así como sobre la crítica situación actual. Concluyó de forma emotiva, entonando el himno nicaragüense en miskito, a capela y a dúo con otra persona de ese pueblo indígena.

\section{Jueves 29 de agosto del 2019, IIS}

8) Mesa sobre Arte y cultura en la revolución.

Ponentes: Sergio Villena, Fidel de Rooy (investigador de FLACSO Costa Rica) e Illimani de los Andes (artista y curadora independiente nicaragüense).

Moderador: Aleksander Aguilar (CLACSO, O Istmo).

Villena realizó una aproximación general a la simbología de Sandino y del sandinismo, así como a las disputas por su imagen en los distintos momentos de la historia revolucionaria y posterior. De Rooy hizo un recuento sintético de las políticas culturales de la revolución, así como de las características del movimiento muralista surgido en los años 80, con base en el libro de David Kunzle. Illimani presentó una aproximación a las nuevas simbologías surgidas durante el gobierno Ortega-Murillo y, particularmente, en las movilizaciones de los "autoconvocados" iniciadas en abril del 2018. Quedó planteada la pregunta de si Sandino vive todavía, es decir, si mantiene su vigencia como símbolo aglutinador, movilizador e inspirador de luchas emancipatorias. 
9) Foro Costa Rica en la revolución.

Panelistas: Manuel Mora, Israel Guillén, María Picado e Ignacio Dobles. Moderadora: Claudia Morales (estudiante Maestría en Sociología, UCR).

Los participantes hicieron un recuento testimonial de la participación costarricense en la insurrección sandinista de 1979; destacaron la dimensión militar, sobre todo en el frente sur, por parte de militantes del partido Vanguardia Popular. Mora destacó el vínculo con la URSS en la formación de cuadros militares, así como cuestiones organizacionales y estratégico militares de la participación costarricense en la insurrección. Guillén se refirió, más bien, a la experiencia vivida por los costarricenses en campo, sobre lo cual también comentó María Picado, quien resaltó el papel de la participación femenina en las acciones militares.

10) Foro Mujeres en la revolución, la contrarrevolución, la posrevolución y la insurrección de 2018.

Panelistas: Ileana Rodríguez, Verónica Rueda, Irene Agudelo y Claudia Morales. Moderadora: Sindy Mora (investigadora IIS).

Las panelistas, que han hecho investigaciones académicas o han sido partícipes de la historia reciente nicaragüense, se posicionaron críticamente respecto a la "prosa de la insurgencia" sandinista, tanto en la década de los ochenta como en el gobierno reciente Ortega-Murillo. Expusieron, a partir de testimonios e información de archivo, pero también de acuerdo con su experiencia personal, acerca de las distintas formas en que las mujeres se involucraron en cada uno de los momentos históricos y destacaron cómo fueron relegadas a un lugar secundario por las jerarquías revolucionarias y contrarrevolucionarias, así como las formas en que ellas mismas se posicionaron y organizaron desde su propia condición femenina en ambos bandos, en la posguerra y en la insurrección del 2018.

Así, Rodríguez contrastó -de acuerdo principalmente con el testimonio de Leticia Herrera- la forma en que el gobierno revolucionario relegó a las mujeres y minimizó sus demandas con las formas de organización y acción de la Asociación Madres de Abril (AMA), destacando el papel de la maternidad y el afecto en la insurrección cívica de 2018. Por su parte, Agudelo señaló cómo durante la guerra frente a la contra el gobierno sandinista incorporó de manera relegada a las mujeres en el SMP y la manera en que la Juventud Sandinista reactivó imaginarios patriarcales que parecían superados con el triunfo revolucionario; en una segunda parte, se refirió a la participación de las mujeres en la contra, la manera en que sus formas y comportamientos fueron masculinizados en el marco de las actividades militares y a las reacciones masculinas frente a los comportamientos sexualmente liberados de algunas combatientes, como fue el caso de La negra. 
Rueda se refirió principalmente a las mujeres que se rearmaron (las remujeres) durante la posguerra para exigir que se cumplieran las promesas y se les dotara de condiciones dignas de vida. Lo anterior dio lugar a la formación de organizaciones -como el caso del colectivo Nora Astorga-, el desarrollo de acciones armadas como la toma de rehenes en Ocotal, negociaciones con el gobierno paradójicamente presidido por una mujer y emprendimientos fallidos -como el caso de la adquisición de máquinas de coser-. Morales presentó sus avances de una investigación que está realizando en la Maestría en Sociología (UCR) sobre la participación de mujeres jóvenes en las movilizaciones estudiantiles que comenzaron en abril del 2018; narró diversas experiencias y testimonios sobre la manera tradicional patriarcal en que las mujeres movilizadas fueron tratadas por sus compañeros de movilización y por los grupos de choque sandinistas y las fuerzas policiales.

En el cierre del foro, destacaron las palabras de la Dra. Rodríguez, quien señaló los avances "a pellizcos" de las reivindicaciones feministas y el paulatino desmontaje del patriarcado; resaltó la importancia actual que el feminismo asigna a la cuestión del cuerpo y a la crítica de la sexualidad masculina.

11) Conferencia y show artístico: El hip hop como expresión política: el caso de Nicaragua explanada IIS.

Aleksander Aguilar Antunes y Fabiola Palacio Murillo (becaria IIS) dialogaron con el rapero Cheyo B sobre la importancia de la cultura hip hop en la insurrección cívica del 2018. Posteriormente, el cantante y compositor nicaragüense refugiado en Panamá interpretó varios temas de su autoría relacionados con la crisis del 2018-2019. El acto finalizó con un número musical a cargo de Mario Rocha, cantante y compositor lírico nicaragüense refugiado en Costa Rica.

La actividad generó un convivio comunitario con participantes en el Encuentro, pero también atrajo a otro público que llegó a escuchar a Cheyo B, incluso a algunos transeúntes que se sumaron a la actividad realizada extramuros del IIS.

\section{Viernes 30 de agosto del 2019, IIS. \\ Campus Rodrigo Facio, San Pedro Montes de Oca}

12) Presentación de Trabajos finales del diplomado "Formación Académica para el Liderazgo Político", organizada por FLACSO Costa Rica.

Presentadora: Ilka Treminio (directora de FLACSO Costa Rica). Moderadora: María Amalia Amador (coordinadora del Diplomado, FLACSO). Expositores: Colectivo “Las chicas subversivas" y colectivo sobre "Justicia transicional".

La directora de FLACSO Costa Rica explicó brevemente la importancia de reflexionar sobre las coyunturas críticas y describió las características del Diplomado, el cual 
estuvo dirigido a apoyar la formación política de activistas y profesionales de origen nicaragüense, en su mayoría refugiados en Costa Rica. Dos grupos de estudiantes expusieron los resultados de su trabajo en el Diplomado, así como las inquietudes y reflexiones sobre el presente y el futuro de Nicaragua.

El primer colectivo fue el de "Las chicas subversivas", compuesto por Mayling Cortez, Meyling Paz, Francis Silva, Cynthia Thais Alfaro y Ximena Castilblanco. Ellas expusieron en modalidad virtual desde Nicaragua el proyecto "Formación política con enfoque feminista como factor empoderador de las jóvenes activistas de los movimientos universitarios insurgentes en el 2018", así como la propuesta de activismo político feminista mediante la elaboración de un blog feminista.

El segundo grupo, conformado por Adriana Gutiérrez, Juan Diego Barberena, Nelson Zeas, Gender Sotelo y Gerssy Noguera, presentó la investigación "Justicia transicional desde el enfoque de la memoria histórica y la no repetición”. Ellos explicaron que en Nicaragua, a diferencia de otros países, al concluir la guerra civil en 1990 no se estableció una comisión de la verdad ni se llevó adelante un proceso de justicia transicional, sino que se implementó una suerte de "política del silencio y el olvido". De acuerdo con un análisis comparativo tomando como referencia otros casos latinoamericanos como Guatemala, Colombia y Argentina, presentaron una propuesta para que eso no vuelva a ocurrir y para que se aborde la cuestión de memoria y de la justicia transicional en Nicaragua como una de las tareas necesarias para resolver la crisis del 2018.

13) Foro Las bases sociales de la rebelión cívica del 2018.

Panelistas: Carlos Sandoval (IIS); Darvin Sánchez (estudiante Maestría en Sociología, UCR); Diana Campos; y Damaso Vargas (representante del Colectivo “Las volcánicas”). Moderadora: Nora Garita (Iniciativa Universitaria por Nicaragua).

Sandoval expuso algunos antecedentes y elementos generales para entender la rebelión de 2018, enfatizando en sus hallazgos obtenidos mediante una investigación estadística que ha realizado sobre jóvenes y expectativas de futuro en Nicaragua y otros países de la región. Sánchez expuso sus avances de investigación sobre la participación de jóvenes universitarios en la rebelión cívica, mientras que Campos reflexionó sobre su experiencia como parte de la Iniciativa Universitaria, destacando las acciones realizadas para atender las necesidades de los jóvenes nicaragüenses que se encuentran en Costa Rica en condición de fugitivos o refugiados. La representante de "Las volcánicas" expuso las especificidades del movimiento LGTBI durante el gobierno de Ortega y Murillo, así como en la rebelión del 2018. 
14) Conversatorio Retos y perspectivas de la Nicaragua actual.

Panelistas: Dolores Figueroa, Verónica Rueda, Alberto Cortés (Escuela de Ciencias Políticas, UCR), Enrique Sáenz (economista nicaragüense, exdiputado por el MRS). Moderador: Sergio Villena.

Las personas participantes enriquecieron el análisis de las "bases sociales de la rebelión" y expusieron sus puntos de vista sobre la situación actual y las perspectivas a futuro. Sáenz destacó principalmente la dimensión económica de la crisis actual y los retos en ese campo; Cortés se concentró en la dimensión de la cultura política y, específicamente, en la tradición caudillista nicaragüense. Por su parte, Rueda y Figueroa señalaron la importancia de la cuestión agraria, la problemática de la costa Caribe y algunos asuntos relacionados con las reivindicaciones de actores hasta ahora relegados, así como el papel de la justicia transicional, el trabajo de la memoria y la búsqueda de reconciliación.

15) Conferencia magistral de cierre Historia como archivo vivo. Estados fallidos y poblaciones bajo amenaza de muerte, a cargo de Ileana Rodríguez.

La conferencista expuso a partir de su libro La prosa de la Contrainsurgencia y dio testimonio de su experiencia durante la revolución, la transición y la crisis reciente, como mujer militante del FSLN y académica durante y después de la revolución. En una segunda parte, hizo un recuento crítico de las actuaciones y agravios cometidos por el gobierno de Ortega y Murillo, así como de las formas de resistencia y contestación al régimen.

\section{Conclusiones generales}

En relación con la Revolución, se realizó un recuento crítico de las principales medidas del gobierno del FSLN entre 1979 y 1990. En particular, se hizo referencia a la reforma agraria, la campaña de alfabetización y las políticas culturales, así como a la promulgación del régimen de autonomía para la costa Caribe y las políticas de género. Se reflexionó acerca de cómo la mayoría de estas medidas pensadas -desde una subjetividad desarrollista de orientación socialista- como progresistas, generaron diversos conflictos y resistencias entre sectores y actores cuyas particularidades no fueron suficientemente consideradas por quienes diseñaron y llevaron adelante esas políticas.

Por ejemplo, se señaló cómo la reforma agraria generó conflictos por las políticas de expropiación, porque se aplicaron no solo a los grandes terratenientes, sino también a medianos y pequeños propietarios, muchos de ellos no vinculados al somocismo; asimismo, se hizo referencia a los problemas generados por las formas de distribución de la tierra, que se realizó no de manera individual o familiar, como esperaban muchos campesinos sin tierra, sino formando colectivos o cooperativas. Además, se hizo énfasis en 
que muchas de las tierras expropiadas terminaron en manos de altos miembros del FSLN, que se constituyeron en nuevos terratenientes; algo similiar ocurrió con propiedades inmuebles urbanas que fueron acaparadas por la nueva elite gobernante mediante "la piñata" de finales de los ochenta.

En cuanto a la campaña de alfabetización, considerada usualmente el mayor logro cultural de la revolución, se señalaron las deficiencias en términos de diseño e implementación entre las poblaciones étnicamente diferenciadas de la costa Caribe, donde fueron vistas como una forma de avasallamiento cultural. Tanto la reforma agraria como la alfabetización generaron conflicto y resistencias entre las poblaciones indígenas de la costa, las cuales se movilizaron y se sumaron a la contra como combatientes y apoyo logístico. Se señaló, asimismo, la importancia de la creación -tardía-de regiones autónomas en la costa y también sus limitaciones.

El Encuentro contribuyó a entender la complejidad de las resistencias a las políticas de la revolución. En particular, se profundizó en la historiografía de la llamada contra, en la cual convergieron distintos grupos, entre ellos exguardias somocistas, pequeños y medianos campesinos que se resistían a las confiscaciones, las poblaciones miskitas de la costa, campesinos descontentos con la distribución de la tierra y otros sectores urbanos y miembros de la burguesía, todo con el apoyo de Estados Unidos. Además, se criticó la manera simplificada en que el gobierno del FSLN construyó al "enemigo Contra" y cómo los grupos movilizados como tropa en ambos frentes participaron -O, más bien, no lo hicieron protagónicamente- en los gobiernos de la posguerra.

Otro aporte del Encuentro fue la discusión sobre el lugar en el gobierno del FSLN al que fueron relegadas las mujeres que habían participado como protagonistas durante la insurrección sandinista y, más tarde, en la guerra civil; se destacaron los casos de Leticia Herrero y de La negra, por ejemplo. Se señaló que, pese al protagonismo, organización y elaboración de una agenda propia de las mujeres, la revolución postergó, minimizó y desestimó muchas de las demandas feministas; incluso, estigmatizó y rechazó ciertos comportamientos y prácticas femeninos -como maquillarse- considerados "burgueses", "superfluos" o "no revolucionarios". La reproducción de comportamientos patriarcales, que incluyó el abuso sexual justificado como aporte "vaginal" a la lucha, tampoco estuvo ausente en la contra, donde hubo una importante participación de las mujeres, pero poco reconocimiento para ellas.

En cuanto a los años noventa, se destacaron, sobre todo, los incumplimientos de las promesas de reconocimiento y redistribución a los desmovilizados, así como las acciones restauradoras. En particular, nuevamente se tocó el tema agrario, que fue abordado por el gobierno de Violeta Barrios, en términos de las indemnizaciones a los grandes propietarios expropiados la década anterior, lo cual redundó en un gran endeudamiento del Estado nicaragüense, sin aportar ningún beneficio a las mayorías empobrecidas por la guerra. Los problemas agrarios quedaron irresueltos y los logros en términos de autonomía étnica regional quedaron librados a su suerte, ya que el gobierno 
actuó por omisión en este rubro. Eso dio lugar a procesos de movilización y rearme, entre los cuales destacó el caso de las "remujeres" de la organización Norma Astorga, quienes llevaron adelante acciones armadas y negociaciones fallidas con el gobierno de Violeta Barrios.

En el ámbito cultural, luego de 1990 fueron abandonadas del todo las políticas de democratización cultural y participación popular, que no estuvieron exentas de ambigüedades, conflictos y contradicciones tampoco durante el gobierno sandinista, en parte por las tensiones entre los liderazgos culturales contrapuestos de Ernesto Cardenal y Rosario Murillo. En lo simbólico, se señaló que la década de los ochenta fue la época de la canonización de Sandino como símbolo de la "nueva Nicaragua", mientras que los noventa fueron un periodo iconoclasta, de destitución simbólica de los íconos establecidos como hegemónicos y oficiales por el sandinismo. Esa década fue también un periodo de reelitización y privatización de la cultura, con una fuerte penetración de la cultura de consumo y la americanización de los patrones del gusto, a la vez que se mantuvo una fuerte tradición popular con amplio contenido católico, pese a la creciente penetración del protestantismo pentecostal.

Las políticas de privatización de la economía continuaron durante el gobierno de Arnoldo Alemán, en el cual se produjo, además, la restauración del patrimonialismo y la corrupción, mientras que en el de Enrique Bolaños se realizó una política de privatización a rajatabla. En este periodo, el FSLN se dividió y se formó el MRS, con una visión más de "nueva izquierda" proclive a un modelo democrático y ciudadano; no obstante, mantuvo un ala más apegada a ideas y prácticas beligerantes, comandado por Daniel Ortega. Esta última estableció una alianza con sectores conservadores, como el PLC de Alemán, el COSEP y los sectores más reaccionarios de la Iglesia, erosionando los avances democráticos, así como los logros en términos de institucionalidad democrática, derechos humanos y la ciudadanía, en especial en términos de género.

En cuanto al retorno del sandinismo "transfigurado" de Ortega y Murillo, se señaló la persistencia de los problemas estructurales -agrarios, así como el retroceso en la cuestión étnico regional y los temas de género. También se señaló el reforzamiento del caudillismo, el retorno del patrimonialismo y clientelismo, así como el extractivismo exacerbado-, agudizado por el proyecto del canal interoceánico, el desarrollo de la minería, el avance de la colonización mestiza y la destrucción del medio ambiente, como el incendio en la Reserva Ecológica Indio Maíz. Se destacó la erosión de la institucionalidad democrática, la limitación de los derechos ciudadanos, la monopolización de los medios de comunicación y el acaparamiento de las oportunidades de empleo, negocios y acceso a los servicios públicos, cada vez más restringidos en beneficio de los miembros del gobierno, sus aliados y sus clientelas.

Todo el conjunto de agravios producido por esas acciones dio lugar a diversas manifestaciones de malestar. Medidas como la prohibición del aborto terapéutico encontraron rechazo entre los movimientos feministas: los conflictos de tierras por el 
avance de la colonización mestiza y el proyecto canalero provocaron movilizaciones campesinas; los incendios en la reserva Indio Maíz y la expansión de las explotaciones mineras fueron cuestionadas por los movimientos ecologistas, mientras las restricciones a los partidos políticos, los fraudes electorales y la cooptación y represión de estudiantes -violatoria de la autonomía universitaria- generaban reacciones diversas. La lista de agravios se extiendo a la reforma de pensiones, que afectaría a la población de adultos mayores, en tanto que las poblaciones LGTBI verían ampliar el acoso por un gobierno aliado con sectores conservadores católicos y evangélicos. Las movilizaciones de estos múltiples actores fueron sistemáticamente reprimidas por el gobierno, con la policía y grupos de choque, que establecieron un control casi absoluto de la calle, impidiendo las manifestaciones públicas de rechazo al gobierno.

Todo el malestar acumulado estalló en abril del 2018. La movilización se masificó y urbanizó en parte gracias a las nuevas tecnologías de la información y la comunicación, así como de la reactivación (y actualización) de un repertorio social de movilización y lucha. En el primer caso, irónicamente, el propio gobierno había ampliado el acceso gratuito a internet en las poblaciones urbanas, que de esa manera pudieron enterarse en tiempo real y con fuentes alternativas de lo que estaba pasando, así como informar sobre lo que ocurría en su entorno, pese al control férreo sobre los medios de comunicación tradicionales que se agudizó con la rebelión, control que incluye el asesinato, persecución y encarcelamiento de periodistas, pero también la confiscación y destrucción de equipos, entre otros.

Por otra parte, los jóvenes urbanos, tanto de la capital como de otras ciudades, se sumaron masivamente a la protesta y retomaron un repertorio de lucha que se formó durante los años de la revolución y que parecía olvidado. En la presentación del libro de CLACSO (en particular, la ponencia de Verónica Rueda), el conversatorio con Cheyo B, en la presentación de "Las chicas subversivas" y en la de Illimani de los Andes, así como en la exposición de Villena, se pudo conocer sobre las nuevas formas de expresión y protesta, tanto en el ámbito de la música, como en la plástica y los nuevos medios.

Entre la apropiación de formas de lucha por los insurrectos destacan las barricadas, los morteros y diversos recursos simbólicos (consignas, cánticos e incluso prácticas religiosas que daban a las marchas un carácter de procesiones o de manifestaciones folclóricas) revolucionarios y religiosos institucionales y populares. En las movilizaciones emergió también un nuevo repertorio simbólico contrapuesto a los nuevos símbolos del gobierno de Ortega y Murillo (cuyo símbolo más importante, los "chayopalos", fueron el blanco preferido de la indignación popular iconoclasta) y a algunos símbolos históricos del sandinismo (en particular, el uso de la bandera nacional, azul y blanco, en oposición a la bandera del FSLN y los colores rojo y negro). No hubo acciones vandálicas o iconoclastas contra la figura icónica de Sandino, pero tampoco un rescate masivo de esta, aunque sí se señalaron algunas resignificaciones, como la imagen de Sandino con el pico rojo o la de su mítico sombrero devenido lazo luctuoso. También se 
pudo conocer nuevas formas de expresión visual, más afín con las formas contemporáneas de artivismo, así como nuevas manifestaciones musicales, afines al hip hop y otros géneros actuales, que amplían la banda sonora de la protesta, que no prescinde del todo de las modalidades que emergieron en los ochenta, como es el caso de los aportes de los hermanos Mejía Godoy, que han devenido opositores el régimen de Ortega y Murillo.

En lo que respecta a las artes visuales, es oportuno señalar que entre las actividades preparatorias del Encuentro, el IIS organizó en abril de 2019 una importante exposición con el artista nicaragüense Marcos Agudelo, quien presentó una obra original titulada Lxs muertxs que nunca mueren. Esa propuesta consistía en una monumental instalación con la cual el autor rendía homenaje a las personas asesinadas por el gobierno de Ortega y Murillo y sus grupos de choque durante la represión que siguió al estallido de abril de 2018, a la vez que vinculaba simbólicamente la insurrección de 2018 con el legado heroico de Sandino, disputando así ese ícono histórico al gobierno actual. En la apertura de la exposición, que tuvo lugar en la "pila de la melaza" del MADC, se realizó también una performance colectiva, en la que estudiantes universitarios nicaragüenses y costarricenses hermanados, leyeron en voz alta y solemne los nombres de todas las personas asesinadas, así como se pidió al público que depositara ofrendas para esas personas. La exposición tuvo una segunda presentación, sin la performance, en la Sede Pacífico de la UCR. ${ }^{2}$

Finalmente, oteando hacia el futuro, en el Encuentro se reflexionó sobre algunos temas relevantes: resolver las contradicciones del modelo económico desarrollista, "renovado" con contenidos neoliberales, promoviendo modalidades sostenibles y medioambientalmente responsables; reestablecer la institucionalidad democrática y los derechos humanos; transformar la cultura necropolítica, caudillista, autoritaria y patriarcal; cuestionar la política sacrificial y fortalecer la participación de la ciudadanía, sobre todo de las mujeres, jóvenes, campesinos y poblaciones étnicamente diferenciadas. También se planteó la pregunta de si Nicaragua ya está en transición y, en todo caso, se consideró fundamental implementar una política de la memoria que genere un archivo de lo sucedido durante la crisis, así como una propuesta de justicia transicional para establecer la verdad de los hechos, castigar a los perpetradores y reparar a las víctimas y sus familiares. Por último, se destacó la importancia de la solidaridad costarricense, tanto durante la revolución como más recientemente, con la insurreción y con población refugiada. 


\section{Notas}

1 Esta relatoría fue escrita en los últimos meses de 2019, pero la revisión permite hacer breve referencia a un hecho que parece estar agudizando estas contradicciones; nos referimos a la manera en que el gobierno de Ortegra y Murillo (no) están gestionando la pandemia generada por la difusión del COVID-19.

2 Se anexa a esta relatoría el texto curatorial incluido en el brochure de la exposición, escrito por Sergio Villena. Siguiendo el vínculo https://m.facebook.com/pg/IIS.UCR/photos/?tab=album\&album_id=1233855996767532\&mt_nav=1 puede verse una galería de imágenes de esta exposición. Entre las actividades preparatorias al Encuentro se incluyeron también dos conversatorios sobre la crisis nicaragüense (Nicaragua, insurrección y después y La crisis de Nicaragua. Conversación con los protagonistas), un ciclo de cine nicaragüense y la presentación del libro Buenas al pleito. Mujeres en la rebelión de Sandino (2019), de Alejandro Bendaña.

\section{Anexo. Texto curatorial}

\section{Lxs muertxs que nunca mueren, de Marcos Agudelo}

\section{Sergio Villena Fiengo}

En su poema "Hora 0" (1960), Ernesto Cardenal interpreta el sentimiento popular y representa a Sandino como el héroe nacional y a Nicaragua como la "patria de Sandino". Con el triunfo de la revolución en 1979, el "general de hombres libres" pasó de ser la inspiración para la rebelión a ser la figura tutelar en la construcción y la defensa de la Nueva Nicaragua. Quienes siguieron su ejemplo y dieron su vida en ese empeño, pasaron -según el discurso hegemónico del momento- a formar parte del panteón de "Los muertos que nunca mueren".

Casi cuarenta años después, estalla en Nicaragua una insurrección en contra del segundo gobierno del FSLN. La protesta popular pacífica y la violenta respuesta del gobierno plantean la pregunta por la actualidad de Sandino: ¿Sandino todavía vive? ¿Sigue siendo un símbolo de emancipación? $\mathrm{O}$, por el contrario ¿es apenas un síntoma de aquello que impide la realización de la nación nicaragüense? ¿Ha llegado la hora de olvidar a Sandino?

A propósito del primer aniversario de la insurreción cívica protagonizada por el pueblo nicaragüense en abril de 2018, Marcos Agudelo presenta Lxs muertxs que nunca mueren, obra que reivindica la contemporaneidad de Sandino. En su propuesta, el héroe nacional, que había sido reducido a una "sombra" vigilante cuando la derrota ética 
y política del FSLN a fines de los ochenta, renace alimentado por la rebeldía de aquellxs mujeres y hombres que murieron por demandar libertad y justicia a un gobierno que se declara sandinista, pero se aleja de los ideales de Sandino.

La pieza es complementaria con la instalación El Cianómetro, colocado durante la X Bienal Centroamericana (2016) en torno al quiosco del parque Central de San José (un regalo del dictador Somoza al presidente Calderón Guardia) que exhibía impresiones intercaladas de los cielos de San José y Managua. Por su parte, Lxs muertxs que nunca mueren se ocupa del "inframundo" simbolizado por el espacio soterrado de la Pila de la Melaza, que escenifica un mausoleo donde se realiza un acto colectivo de duelo que elabora sobre la relación entre el legado de Sandino, la deriva del sandinismo y la insurrección del 2018.

Esta obra propone una fusión entre Sandino y las víctimas del sandinismo transfigurado, tanto en relación con su muerte física como con su trascendencia espiritual. Las muertes corporales son representadas por las piedras teñidas de sangre, posadas sobre el piso, en el mundo terrenal; la trascendencia hacia una nueva vida es representada por las candelas, ubicadas en un espacio suspendido (trascendente/ascendente). La pieza utiliza 535 candelas, que simbolizan el número de los asesinados y desaparecidos durante la represión del 2018, según datos de la ANPDH.

Pero las víctimas ajustan también cuentas con el legado de Sandino. Rechazan la tradición sacrificial de la política nicaragüense y entonan una nueva consigna: Matria libre o vivir. Por eso, el Sandino renacido no es ya una figura patriarcal erguida, que convoca a la lucha armada o ejerce una severa mirada vigilante; es más bien una figura horizontal y femenina, un camposanto/altar materno, que llama a la construcción pacífica de una sociedad democrática.

Este Sandino-Coatlicue es una figura espectral doble: terrenal, compuesta por despojos sangrantes (piedras); trascendente, formada por espíritus (candelas). Las veladoras representan las almas de los asesinados -la vela es un símbolo del amor, lo mismo que de la muerte-. Las piedras rojas representan órganos vitales de las víctimas, formando un collar de corazones dispuestos en un sacrificio -ojalá el último en la trágica historia de Nicaragua- que representan el renacer de la vida.

En lo horizontal ambas capas, la terrenal y la trascendente, forman el contorno de la silueta de Sandino-Coatlicue. En lo vertical, se sobreponen y perfilan la imagen insurreccional de un volcán: las sangrantes lápidas/corazones son una base de lava que bulle y enciende el volcán que forman las candelas. El suave movimiento oscilante de las velas y del bosque de alambres que las suspenden, provocado por la brisa que cruza el mausoleo, evoca la calma trepidante de un volcán a punto de hacer erupción.

El catalizador de esa resignificación emancipadora será el encuentro solidario entre lxs refugiadxs nicaragüenses y lxs costarricenses que les acompañamos en su duelo. La performance colectiva que se realizará durante la inauguración de la obra prenderá la lumbre de las candelas, evocará sus nombres rendirá homenaje al legado 
de Lxs muertxs que nunca mueren. Ese soplo solidario, que culminará con la lectura de unos versos de Cardenal a propósito de lxs muertxs de abril y el renacer de la vida en el mes de mayo, alimentará la esperanza de una nueva Hora 0 para Nicaragua.

Sergio Villena Fiengo. Costarricense-boliviano. Doctor en Estudios de la Sociedad y la Cultura (Universidad de Costa Rica). Actual director del Instituto de Investigaciones Sociales de la Universidad de Costa Rica.

Contacto: sergio.villena@ucr.ac.cr

ORCID: https://orcid.org/0000-0002-2864-8816 